\title{
Bending Alters Water Balance and Reduces Photosynthesis of Rose Shoots
}

\author{
Soo-Hyung Kim ${ }^{1}$ \\ Department of Environmental Horticulture, University of California, Davis, CA 95616
}

Kenneth A. Shackel

Department of Pomology, University of California, Davis, CA 95616

J. Heinrich Lieth

Department of Environmental Horticulture, University of California, Davis, CA 95616

\begin{abstract}
AdDitional INDEX wORDS. Rosa hybrida, transpiration, stomatal conductance, water potential, photosynthesis model, cut-flower, greenhouse crop

ABstract. Shoot-bending has become a standard cultural practice in cut-flower rose (Rosa hybrida L.) production. Physiological effects of shoot-bending on leaf net photosynthesis $(A)$, stomatal conductance $\left(g_{s}\right)$, transpiration rate $(E)$, and stem water potential $(\psi)$ were investigated for rose plants. With saturating light conditions, shoot-bending decreased rates of $A, g_{s}$, and $E$ in comparison with the rates prior to shoot-bending. $A, g_{s}$, and $E$ of bent shoots were significantly lower than those of the control shoots that were not bent. The differences in $A$ between bent and control shoots decreased over time, disappearing within 3 weeks after bending. Bent shoots exhibited reduced $\psi$. Leaves projecting upward on a bent stem were found to have higher $A, g_{s}$, and $E$ than those projecting downward. This was probably due to the destruction of xylem vessels serving the leaves attached to the lower side (compression side) of the bent stem. Our results support the hypothesis that hydraulic conductivity is reduced in bent shoots probably due to disturbed xylem tissues, and that reduced photosynthetic rates of bent shoots are a function of water status.
\end{abstract}

In commercial rose production for cut-flowers, shoot-bending has become a standard growing technique in conjunction with container-based soil-less media culture. Rose growers have been replacing or augmenting pruning with bending where nonproductive shoots are bent down into the canopy or toward the aisle. It is thought that shoot-bending results in increased foliage area to intercept light for photosynthesis by forming an extended horizontal canopy of bent shoots. Therefore, in terms of utilization of resources, plants would benefit from the increased capture of light falling between rows. Kool and Lenssen (1997) reported that increased light interception was achieved by shoot-bending during the period of basal-shoot formation. As a consequence, plant growth rate was increased. Kim and Lieth (2004) reported that applying shoot-bending to nonproductive shoots resulted in increased stem length of harvestable flowering shoots at the expense of the number of flowering shoots per unit ground area. It has also been speculated that shoot-bending may break apical dominance by changing the hormonal balance within the plant and promoting the formation of axillary shoots (Cline, 1991; Hosokawa et al., 1990).

The flower bud is normally removed when bending a shoot in the commercial greenhouses. Studies suggest that removal of any plant parts or changing the plant structure in any manner may

Received for publication 10 Nov. 2003. Accepted for publication 15 Mar. 2004. We thank Alexandra Rosati and Jonathan Guan from the NSF Young Scholars Program for carrying out stem water potential measurements and preliminary photosynthesis measurements, respectively. We thank Drs. Loren Oki and Mark Roh for helpful comments on the manuscript. We also thank Dr. Mike Parrella for letting us use the photosynthesis system. This research was supported in part by grants from the California Cut Flower Commission and the Kee Kitayama Research Foundation, and the Joseph H. Hill Memorial Foundation.

${ }^{1}$ Corresponding author and present address: Soo-Hyung Kim, USDA-ARS, Alternate Crops and Systems Laboratory, Bldg. 001 Rm. 342, BARC-W, Beltsville, MD 20705. Tel: (301) 504-5343; Fax: (301) 504-5823; e-mail: sookim@asrr.arsusda.gov change the balance of source and sink relations as well as the water relations in the plant (Heichel and Turner, 1983; Larson, 1998; Pinkard and Beadle, 1998). This in turn could give rise to changes in the rates of photosynthesis, transpiration, and stomatal conductance. Rose plants in the commercial greenhouses are disturbed throughout the year by practices such as harvesting, pruning, pinching, and shoot-bending. The effects of some of these practices on growth and production of cut-flower roses have been reported (Faber and White, 1977; Zieslin and Mor, 1981).

The objectives of the study were to assess how shoot-bending influences gas-exchange characteristics of rose plants and to determine the associated physiological mechanisms. We measured the rates of net photosynthesis $(A)$, transpiration $(E)$, and stomatal conductance to water vapor $\left(g_{\mathrm{s}}\right)$ of rose leaves before and after shoot-bending. We also measured the stem water potential $(\psi)$ of bent and control (erect) shoots. As the flower bud is usually removed when a shoot is bent, we investigated the effect of flower removal on gas-exchange rates in combination with shoot-bending. We tested the hypothesis that shoot-bending decreases the rates of photosynthesis, transpiration and stomatal conductance as a consequence of impaired water transport due to bending.

\section{Materials and Methods}

Plant culture for gas-exchange experiments. Three-yearold 'Kardinal' rose plants grafted onto 'Natal Briar' rootstock in May 1997 were grown in the greenhouse in the Dept. of Environmental Horticulture at the Univ. of California, Davis. The plants were grown in UC Mix [1 sand : 1 redwood sawdust : 1 peatmoss $(\mathrm{v} / \mathrm{v})]$ in $8-\mathrm{L}$ containers. The bending treatment was applied to individual shoots, which were the experimental units. Individual plants were used as blocks. An automated, tensiometer-based irrigation system with set points of 1.0 and $3.0 \mathrm{kPa}$ irrigated the plants with modified half-strength Hoagland's Solution No. 2 plus 
micronutrients (Oki et al., 2001). Plants were grown under natural light. The air temperature set points inside the greenhouse were $24^{\circ} \mathrm{C}$ in the day to $20^{\circ} \mathrm{C}$ at night. Average daily air temperature was maintained between 18 and $24^{\circ} \mathrm{C}$.

Gas-exchange Expt. 1. The effect of shoot-bending on leaf gas-exchange was determined using seven 'Kardinal' rose plants from Nov. 2000 to Jan. 2001. Two young flowering shoots at a similar stage of development were selected on each plant. One shoot was carefully bent down at the internode above the second leaf with five leaflets from the base (Fig. 1A). The second shoot (control) remained unbent and erect. A young fully expanded five-leaflet leaf ( $\approx 20 \mathrm{~d}$ after unfolding) in the middle (position 2 ; Fig. 1A) of each shoot was selected for the gas-exchange measurements. Leaf age was determined by recording the unfolding date of the selected leaves to ensure that leaves of similar ages were used for the measurements. Gas-exchange measurements were carried out on bent and erect shoots before applying shootbending (day 0 ), then $1,3,5,7,14,21$, and $35 \mathrm{~d}$ after bending repeatedly using the same leaves. Photosynthetic light responses were generated using a photosynthesis system (LI6400; LI-COR, Lincoln, Neb.) with a red/blue LED light source (LI6400-02B) at photosynthetically active radiation $(P A R)$ levels of 2000, 1500, $1000,500,200,100,50$, and $0 \mu \mathrm{mol} \cdot \mathrm{m}^{-2} \cdot \mathrm{s}^{-1}$, and ambient $\mathrm{CO}_{2}$ concentration $\left(360 \mu \mathrm{mol} \cdot \mathrm{mol}^{-1}\right)$. Leaf temperature and relative humidity inside the leaf chamber were kept at $25^{\circ} \mathrm{C}$ and near $50 \%$, respectively. The rates of $A, g_{s}$, and $E$ at saturating light conditions $\left(P A R=1500 \mu \mathrm{mol} \cdot \mathrm{m}^{-2} \cdot \mathrm{s}^{-1}\right)$ were used for analyzing the effect of bending. Paired $t$ tests were used for comparisons of the gas-exchange rates between erect and bent shoots for each measured date, and between before (day 0 ) and $7 \mathrm{~d}$ after bending (day 7) of the same shoots.

To assess how shoot-bending affects photosynthetic light response properties, the following model (Pasian and Lieth, 1989) for leaf net photosynthesis $(A)$ as a function of $P A R$ was used:

$$
A=\frac{\alpha I+A_{\max }-\sqrt{\left(\alpha I+A_{\max }\right)^{2}-4 \alpha I A_{\max } \theta}}{2 \theta}-R_{d}
$$

The parameters are quantum efficiency $(\alpha)$, photosynthetic capacity $\left(A_{\max }\right)$, and curvature factor $(\theta)$. PAR is represented by $I$ and $R_{d}$ is leaf dark respiration rate. Data from individual leaves measured 0 and $7 \mathrm{~d}$ after bending was fitted to the model to test if shoot-bending alters the photosynthetic parameters of the model. Differences between parameter estimates of individual leaves on erect and bent shoots were tested using analysis of variance (ANOVA).

Gas-Exchange Expt. 2. Eight 'Kardinal' rose plants with several developing shoots at similar stages were randomly selected. A $2 \times 2$ factorial experiment in a randomized complete-block design with each plant serving as a block (shoot-bending vs. control; flower bud removal vs. intact) was conducted. Four young flowering shoots at a similar stage of development were selected on each plant. Two shoots were bent down at the internode above the second leaf (five-leaflet leaf) from the base (Fig. 1A). The other two shoots remained unbent and erect. Flower buds were removed using shears from one bent shoot and one control shoot. Five leaflet leaves at three different positions were selected from each stem (Fig. 1A): close to the flower bud (position 1), middle (position 2), and proximal to the base (position 3). The orientation of the leaves immediately after shoot-bending was recorded (i.e., the direction that the terminal leaflet points: upward, horizontal,
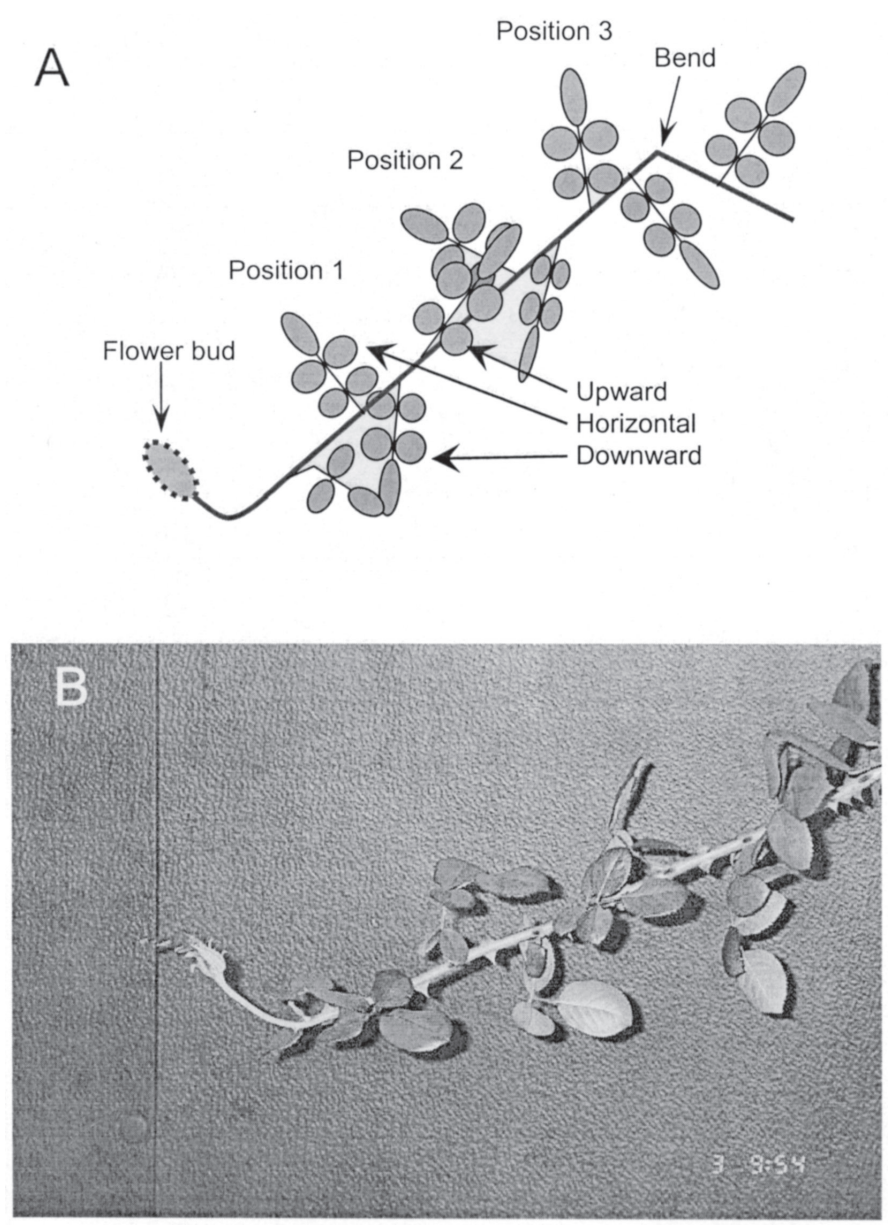

Fig. 1. Simplified illustration (A) and photograph (B) of a bent rose shoot $4 \mathrm{~d}$ after bending. Stem was bent towards the ground at the internode above the second leaf from the base. Five-leaflet leaves in the middle (position 2) of the shoot were used for gas-exchange Expt. 1. Five-leaflet leaves at three different positions: close to the flower bud (position 1), middle (position 2), and proximal to the base (position 3) were used for gas-exchange Expt. 2.

or downward). Gas-exchange rates $\left(A, g_{s}\right.$, and $\left.E\right)$ of the leaves were measured using the LI6400 with the terminal leaflet before bending (day 0 ), then 2 and $7 \mathrm{~d}$ after bending. The gas-exchange measurements were made under light saturated conditions $(P A R=$ $\left.1500 \mu \mathrm{mol} \cdot \mathrm{m}^{-2} \cdot \mathrm{s}^{-1}\right)$ using the LED light source at a leaf temperature of $25^{\circ} \mathrm{C}$ and ambient $\mathrm{CO}_{2}$ concentration $\left(360 \mu \mathrm{mol} \cdot \mathrm{mol}^{-1}\right)$. Data collected $2 \mathrm{~d}$ after bending were used to examine the effects of shoot-bending and flower removal on the gas-exchange properties using analysis of covariance (ANCOVA). Values collected before the treatment (day 0) were used as the covariable for adjustment. Three-way ANCOVA accounting for the effects of shoot-bending, flower removal, and leaf position revealed that all interactions involving leaf position were not significant at $P=0.05$. Based on this result, pooled values over the three leaf positions for each stem were used for testing the effects of shoot-bending and flower removal in order to get the values more representative of the whole shoot. A separate ANCOVA was performed to test the hypothesis that the effects of bending on gas-exchange rates vary with the orientation of the leaves on bent shoots. SAS PROC GLM (SAS system for windows version 8.02; SAS Inst., Cary, N.C.) was used for the statistical analyses. Because ANCOVA was applied, least square means (LSM: adjusted means accounting for covariables) were used to represent the means, and Tukey-Kramer method was used for mean separation. 
Plant Culture for water potential EXPeriment. Three-yearold 'Fire N Ice' rose plants grafted onto 'Natal Briar' rootstock were used for measuring stem water potential. Plants were located in the same greenhouse as described above and grown in 12-L containers filled with a layer of expanded clay pellets and coconut coir (Systems USA, Watsonville, Calif.). Plants were grown in two canopy regimes: hedge (without bent shoots) and bent (with bent shoots) plants. Plants were fertigated several times a day with modified half-strength Hoagland's solution plus micronutrients. Containers were irrigated to leaching four times per day and moisture tension of the root zone was maintained near $1 \mathrm{kPa}$. More detailed description on the plant culture of this experiment was previously published (Kim and Lieth, 2004)

STEM WATER POTENTIAL MEASUREMENTS. Water potential measurements were made at four times of day $(10: 30,12: 50,15: 10$, and 17:30), each day from 18-21 July 2000. Stem water potential $(\psi)$ was measured with a pressure chamber by enclosing either the terminal leaflet or a leaflet pair in an aluminized Mylar envelope and allowing at least $10 \mathrm{~min}$ for equilibration before removal of the leaf or leaflet from the plant, as described by Fulton et al. (2001). No systematic differences were found for $\psi$ measurements made on adjacent leaves when using the whole leaf or different leaflet types (data not presented) and so it was possible to utilize a single leaf (one terminal plus three to four leaflet pairs) for multiple $\psi$ measurements at the same canopy position. Four hedge plants and four bent plants were randomly selected, and at each sampling time, $\psi$ was measured at a specific canopy position in all plants. Canopy positions are described as "upper" (apical) and "lower" (basal), where the erect and bent shoots of the bent canopy correspond to the upper and lower positions, respectively, of the hedge plants. It should be noted that for the hedge plants, the lower and upper positions are considered to be along the same hydraulic pathway (i.e., the positions are in series), whereas in the bent plants the two positions are on parallel pathways. Hence, for hedge plants, $\psi$ is expected to decrease consistently from lower to upper positions, whereas for bent plants $\psi$ of both positions may be similar. The experiment was analyzed as a split-plot design with canopy types (hedge and bent) as wholeplot and canopy positions (upper and lower) as subplot. An average was taken for each position of each canopy type over different days. Because the effect of different time of measurements was not of interest, the averages were used for analysis using SAS MIXED procedure (Littell et al., 1996). The hypotheses tested were: 1) main effect of canopy type; 2) main effect of canopy position; 3 ) interaction between canopy type and position; and 4) simple effect of canopy position within each canopy type. In addition, orthogonal contrasts were performed to test the hypotheses that pooled $\psi$ of hedge canopy (i.e., mean of upper and lower for hedge canopy) is not different than: 1) $\psi$ of upper position of bent canopy (i.e., Table 1 . Net photosynthetic rate $(A)$, stomatal conductance $\left(g_{s}\right)$, and transpiration rate $(E)$ under light erect shoots of bent canopy) and 2) $\psi$ of saturated conditions $\left(P A R=1500 \mu \mathrm{mol} \cdot \mathrm{m}^{-2 \cdot \mathrm{s}^{-1}}\right)$ of leaves on erect and bent rose shoots before and 7 lower position of bent canopy (i.e., bent shoots of bent canopy).

\section{Results}

Morphological adjustment to $P$ SHOOT-BENDING. When shoot-bending was applied, rose plants displayed changes in their morphology (Fig. 1B). Within $1 \mathrm{~d}$ after shoots were bent, the terminal flower bud started turning upward, followed by a similar response in the leaves. Leaves sequentially reoriented the adaxial surfaces upward from the distal end to the bend in the stem. Most leaves reoriented within 4 to $5 \mathrm{~d}$ after bending.

EFFECT OF SHOOT-BENDING ON GAS-EXCHANGE. The rates of $A$, $g_{s}$, and $E$ prior to the shoot-bending treatment were not different between erect and bent shoots (Table 1). These values were used as controls for testing the effect of bending within the same shoot. Comparing the values before and $7 \mathrm{~d}$ after the bending treatment was applied within each shoot, the rates of $A, g_{s}$, and $E$ on erect shoots did not alter in $7 \mathrm{~d}$, whereas those on bent shoots reduced significantly after bending (Table 1). Leaves on bent shoots had lower rates of $A, g_{s}$, and $E$ than erect shoots, $7 \mathrm{~d}$ after the shootbending treatment (Table 1). Reduction in the rates of $A$, and $g_{s}$ was detectable $1 \mathrm{~d}$ after bending (Fig. 2). The difference in $A$ between erect and bent shoots disappeared $21 \mathrm{~d}$ after bending. The differences in the rates of $g_{s}$ and $E$ were not significant 14 $\mathrm{d}$ after bending.

Prior to bending, leaves on erect and control shoots had similar values of photosynthetic light response curve parameters: $\alpha, A_{\max }$ $\theta$, and $R_{d}$ (Fig. 3). Values for these parameters on leaves from erect shoots were similar at day 0 and $7 \mathrm{~d}$ later. $A_{\max }$ of leaves on bent shoots was lower than leaves on erect shoots $7 \mathrm{~d}$ after bending $(P=0.002)$. All other parameters $\left(\alpha, \theta\right.$, and $\left.R_{d}\right)$ were not affected by shoot-bending.

EFFECTS OF SHOOT-BENDING AND FLOWER REMOVAL IN RELATION TO LEAF POSITION. The effects of shoot-bending and flower removal on gas-exchange parameters were examined at three different leaf positions. Leaf position did not alter the effects of shoot-bending and flower removal on $A, g_{s}$, and $E$ as none of the interactions involving leaf position was significant (data not shown).

Using pooled values over the leaf positions $2 \mathrm{~d}$ after bending, ANCOVArevealed that shoot-bending and flower removal resulted in significant reduction in $A$ and $E$ (Table 2). Their interactions were not significant at $P=0.05$. Flower removal did not appear to affect $g_{s}$ while shoot-bending did.

EFFECT OF LEAF ORIENTATION. Leaves oriented downward after bending exhibited reduced rates of $A, g_{s}$, and $E$ than those oriented upward. No difference was apparent between the leaves oriented horizontally and downward (Table 3).

Stem Water Potential. Stem water potential $(\psi)$ of hedge plants were -0.46 and $-0.42 \mathrm{MPa}$ for upper and lower portions, respectively (Fig. 4). For bent plants, they were -0.44 and -0.70 MPa for upper (erect) and lower (bent) positions, respectively (Fig. 4). Marginal interaction between canopy types and positions $(P=0.052)$ was observed, whereas neither main effect (i.e., canopy type and position) was significant. In bent plants, lower position (bent shoots) exhibited lower water potential than $\mathrm{d}$ after shoot-bending treatment was applied.

\begin{tabular}{|c|c|c|c|c|c|c|c|c|c|}
\hline \multirow[b]{2}{*}{$\operatorname{hoot}^{2}$} & \multicolumn{3}{|c|}{$A\left(\mu \mathrm{mol} \cdot \mathrm{m}^{-2} \cdot \mathrm{s}^{-1}\right)$} & \multicolumn{3}{|c|}{$g_{s}\left(\mathrm{~mol} \cdot \mathrm{m}^{-2} \cdot \mathrm{s}^{-1}\right)$} & \multicolumn{3}{|c|}{$E\left(\mathrm{mmol} \cdot \mathrm{m}^{-2} \cdot \mathrm{s}^{-1}\right)$} \\
\hline & Before & After & $P>|t| \mathrm{s}$ & Before & After & $P>|t|$ & Before & After & $P>|t|$ \\
\hline & $18.0^{x}$ & 18.9 & 0.265 & 0.56 & 0.58 & 0.681 & 5.4 & 5.8 & 0.382 \\
\hline & 18.2 & 15.9 & 0.042 & 0.54 & 0.40 & 0.003 & 5.9 & 4.9 & 0.048 \\
\hline$|t|^{\mathrm{w}}$ & 0.187 & 0.001 & & 0.722 & 0.004 & & 0.203 & 0.013 & \\
\hline
\end{tabular}

${ }^{{ }^{z} \text { Erect }}=$ unbent stem (control); bent $=$ stem was bent at the internode above the second leaf from the base.

yProbability from paired $t$ test comparing values before and $7 \mathrm{~d}$ after bending from the same leaves xMean values of seven replicates

wProbability from paired $t$ test comparing values of erect and bent shoots on each day. 


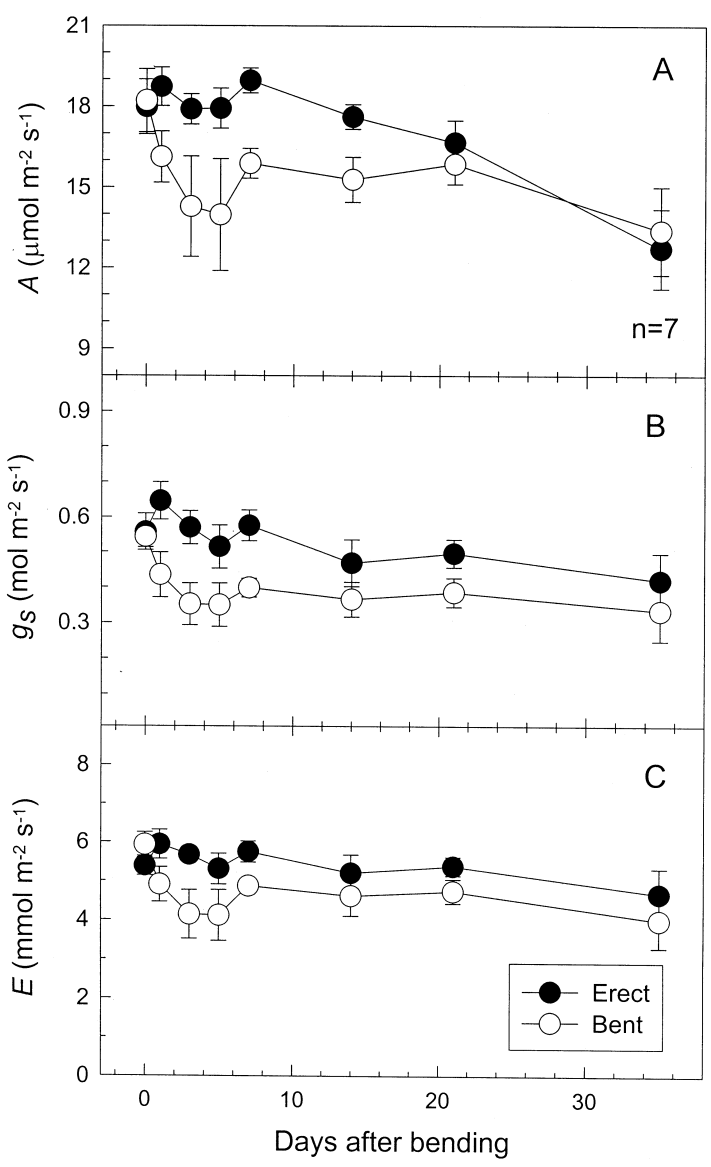

Fig. 2. (A) Leaf net photosynthesis (A), (B) stomatal conductance $\left(g_{s}\right)$, and $(\mathbf{C})$ transpiration rate $(E)$ under light saturated conditions $\left(P A R=1500 \mu \mathrm{mol} \cdot \mathrm{m}^{-2} \cdot \mathrm{s}^{-1}\right)$ of leaves from erect (filled circles) and bent (open circles) rose shoots for $35 \mathrm{~d}$ after the bending treatment was applied. Error bars represent standard errors $(n=7)$.
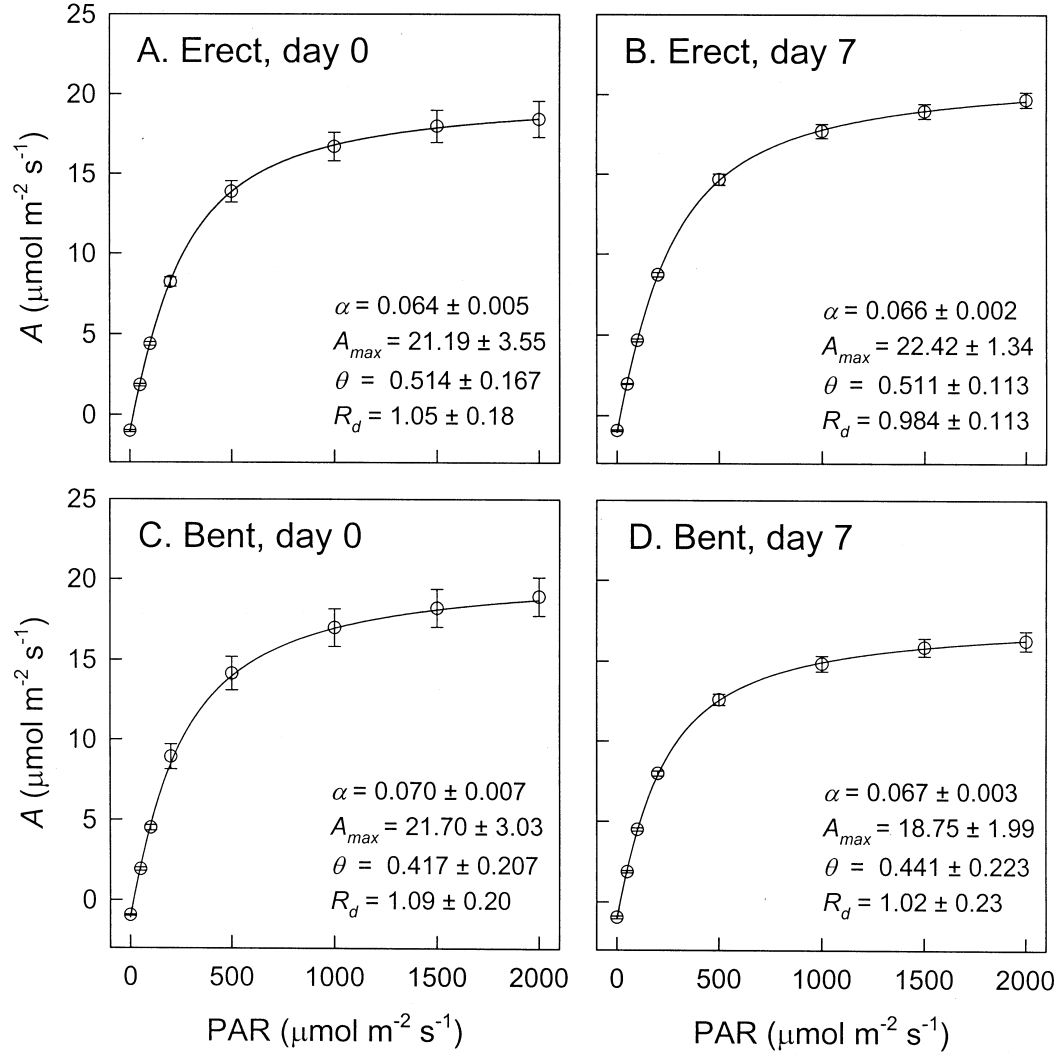

Fig. 3. Photosynthetic response of leaves on erect $(\mathbf{A}, \mathbf{B})$ and bent $(\mathbf{B}, \mathbf{C})$ rose shoots to photosynthetically active radiation $(P A R)$. Lines represent model predictions according to Pasian and Lieth (1989) of leaves prior to bending (day 0) (A,C) and $7 \mathrm{~d}$ later (day 7) (B, D). $\alpha=$ quantum efficiency, $A_{\max }=$ photosynthetic capacity, $\theta=$ curvature factor, and $R_{d}=$ leaf dark respiration rate. Error bars on data points represent standard errors of measured values $(n=7)$. upper position (erect shoots) $(P=0.025)$, whereas no difference was found between lower and upper positions in hedge plants. Orthogonal contrasts revealed that $\psi$ of hedge plants was no different than that of erect shoots of bent canopy, while bent shoots of bent plants exhibited significantly lower $\psi$ than entire hedge plants $(P=0.039)$.

\section{Discussion}

The results from gas-exchange and water potential measurements indicated that shoot-bending altered the water balance of the bent shoot and consequently resulted in reduced rates of $A$, $g_{s}$, and $E$. These reductions appeared $1 \mathrm{~d}$ after shoot-bending was imposed. They may take place as soon as the shoot is bent, because bending could disturb the water balance of the plant instantaneously. The extent of the reduction varied considerably among plants and leaves indicating that the severity of bending may govern the degree of water stress on a bent shoot. Raviv and Blom (2001) reviewed that the leaf water potential of roses usually falls between -0.4 and $-1.0 \mathrm{MPa}$, and discussed that cultural practices such as continual flower harvests in combination with continued production of young leaves could make rose plants very sensitive to water stress. Frederickesen et al. (1994) reported that in loblolly pine, stem bending resulted in a $30 \%$ loss of conducting sapwood area and reduced sapwood permeability. Bending results in compression of xylem vessels on one side and tension on the other side. When bending is severe, the xylem vessels are essentially nonfunctional in water conduction. Xylem tissues damaged by bending may suffer from air embolisms that interfere with water transport. Rather large variability in net photosynthesis from 1 through $5 \mathrm{~d}$ after bending may have resulted from variation in the extent of damage to xylem due to the bending process (Fig. 2). The variability appeared to taper off around $7 \mathrm{~d}$ after bending (Fig. 2).

Differences in $A$ were no longer observed 3 weeks after bending (Fig. 1). Photosynthetic capacity $\left(A_{\max }\right)$ in rose leaves has been reported to vary with leaf age (Pasian and Lieth, 1989) and leaf nitrogen content (Gonzalez-Real and Baille, 2000). The uppermost leaves of flowering rose shoots were found to show higher $A$ with higher nitrogen content than the bottom ones, which pattern appeared to correspond with the light profile inside the canopy (Gonzalez-Real and Baille, 2000). In fully expanded young leaves, biochemical photosynthetic capacity is thought to be maximal and does not impose a critical limitation in actual photosynthetic rates (Harper, 1989). This declination of $A_{\max }$ over the life span of a leaf is seen to be closely related to reduction in leaf nitrogen content (Field, 1983). From our measurements of $A$ of young fully expanded leaves, we hypothesized that decreases in $A$ observed in the young leaves of the bent shoots will be mostly due to stomatal limitation. In other words, intercellular $\mathrm{CO}_{2}\left(C_{i}\right)$ was limited because of reduced $g_{s}$ as water flow was limited due to bending. As leaves grow old, leaf nitrogen con- 
Table 2. Net photosynthetic rate $(A)$, stomatal conductance $\left(g_{s}\right)$, and transpiration rate $(E)$ under light saturated conditions $(P A R=1500$ $\mu \mathrm{mol} \cdot \mathrm{m}^{-2} \cdot \mathrm{s}^{-1}$ ) of rose leaves on erect and bent shoots (with or without flower) $2 \mathrm{~d}$ after the treatments (bending and flower removal) were applied.

\begin{tabular}{llccc}
\hline Shoot & Flowery & $\begin{array}{c}A \\
\left(\mu \mathrm{mol} \cdot \mathrm{m}^{-2} \cdot \mathrm{s}^{-1}\right)\end{array}$ & $\begin{array}{c}g_{s} \\
\left(\mathrm{~mol} \cdot \mathrm{m}^{-2} \cdot \mathrm{s}^{-1}\right)\end{array}$ & $\begin{array}{c}E \\
\left(\mathrm{mmol} \cdot \mathrm{m}^{-2} \cdot \mathrm{s}^{-1}\right)\end{array}$ \\
\hline Erect & Intact & $18.13 \mathrm{a}^{\mathrm{x}}$ & $0.577 \mathrm{a}$ & $6.04 \mathrm{a}$ \\
& Removed & $17.55 \mathrm{a}$ & $0.575 \mathrm{a}$ & $5.94 \mathrm{a}$ \\
Bent & Intact & $15.56 \mathrm{~b}$ & $0.414 \mathrm{~b}$ & $4.97 \mathrm{~b}$ \\
& Removed & $13.31 \mathrm{c}$ & $0.343 \mathrm{~b}$ & $4.10 \mathrm{c}$ \\
$P>$ Fw & Bending & $<0.001$ & $<0.001$ & $<0.001$ \\
& Flower & 0.015 & 0.136 & 0.032 \\
& Interaction & 0.102 & 0.171 & 0.085
\end{tabular}

${ }^{\mathrm{z} \text { Erect }}=$ unbent stem $($ control); bent $=$ stem was bent at the internode above the second leaf from the base.

yIntact $=$ flower bud was not removed from the shoot; removed $=$ flower bud was removed.

xLeast square means (LSM) of eight replicate shoots adjusted by the values before bending. Values were pooled over three leaf positions for each shoot. Means with the same letter within a column are not significantly different by Tukey-Kramer method of multiple comparison at $P \leq 0.05$.

wProbability values of analysis of covariance.

Table 3 . Net photosynthetic rate $(A)$, stomatal conductance $\left(g_{s}\right)$ and transpiration rate $(E)$ under light saturated conditions $(P A R=1500$ $\mu \mathrm{mol} \cdot \mathrm{m}^{-2} \cdot \mathrm{s}^{-1}$ ) of leaves projecting upward, horizontal, and downward on bent rose shoots $2 \mathrm{~d}$ after bending.

\begin{tabular}{lrccc}
\hline $\begin{array}{l}\text { Leaf } \\
\text { orientation }\end{array}$ & $\mathrm{n}^{\mathrm{y}}$ & $\begin{array}{c}A \\
\left(\mu \mathrm{mol} \cdot \mathrm{m}^{-2} \cdot \mathrm{s}^{-1}\right)\end{array}$ & $\begin{array}{c}g_{s} \\
\left(\mathrm{~mol} \cdot \mathrm{m}^{-2} \cdot \mathrm{s}^{-1}\right)\end{array}$ & $\begin{array}{c}E \\
\left(\mathrm{mmol} \cdot \mathrm{m}^{-2} \cdot \mathrm{s}^{-1}\right)\end{array}$ \\
\hline Upward & 12 & $16.79 \mathrm{a}^{\mathrm{x}}$ & $0.486 \mathrm{a}$ & $5.50 \mathrm{a}$ \\
Horizontal & 15 & $14.49 \mathrm{ab}$ & $0.374 \mathrm{ab}$ & $4.37 \mathrm{~b}$ \\
Downward & 9 & $13.08 \mathrm{~b}$ & $0.316 \mathrm{~b}$ & $3.92 \mathrm{~b}$ \\
$P>$ Fw & & 0.007 & 0.025 & 0.007 \\
\hline
\end{tabular}

${ }^{\mathrm{z} U p w a r d}=$ leaves pointing upward after bending; horizontal $=$ leaves pointing horizontally after bending; downward = leaves pointing downward after bending.

$\mathrm{y}_{\mathrm{n}}=$ number of leaves.

xLeast square means (LSM) of leaves adjusted by the values before bending. Means with the same letter within a column are not significantly different by Tukey-Kramer method of multiple comparison at $P \leq 0.05$. wProbability values of analysis of covariance.

tent will decline while the bending damage on water flow might recover over time. This might cause a shift in the limitation in photosynthesis from stomata $\left(\mathrm{CO}_{2}\right.$ supply) to biochemistry $\left(\mathrm{CO}_{2}\right.$ demand). When the supply of neither $\mathrm{CO}_{2}$ nor light is limiting, the utilization rates of these resources could limit photosynthesis (Sharkey, 1985). The utilization of $\mathrm{CO}_{2}$ and light is determined by photosynthetic enzymes, including Rubisco, and in $\mathrm{C}_{3}$ plants these photosynthetic enzymes were shown to degrade in the early phase of leaf senescence (Hortensteiner and Feller, 2002). This transition from stomatal to biochemical limitations could be one of the possible mechanisms to account for the observation that the difference in $A$ between erect and bent shoots disappeared with leaf age while this pattern was not as obvious in $g_{s}$ and $E$ (Fig. 2). The damage in xylem tissues caused by bending might recover over time as the formation of callus around the bent area has been frequently observed. Plant hormones such as ethylene or auxin could be involved in such processes (Mitchell, 1996). The reorientation of flower bud a few days after bending (Fig. 1B) demonstrates the involvement of auxin.

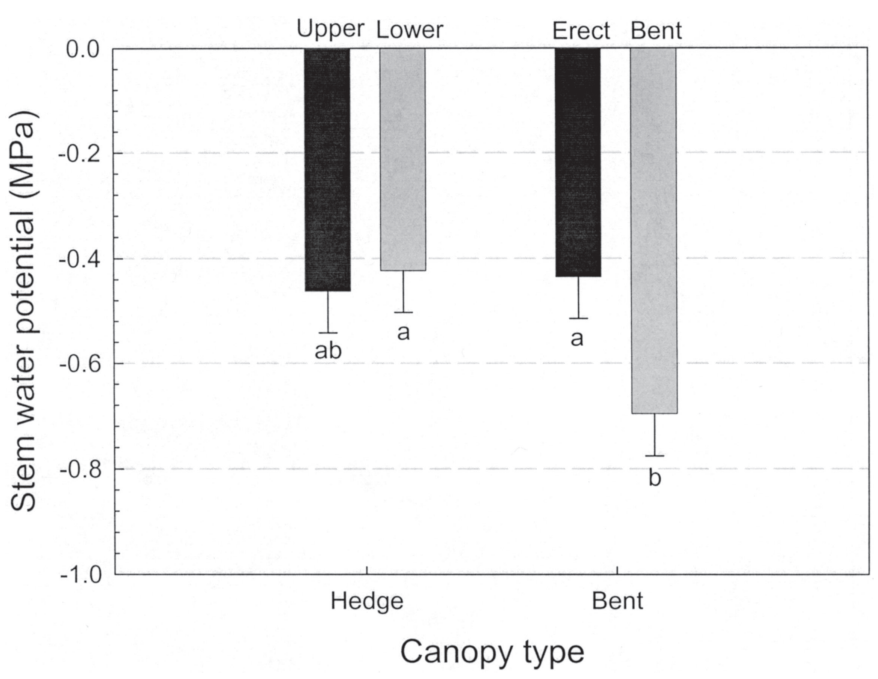

Fig. 4. Stem water potential $(\psi)$ of upper and lower portion of hedge canopy, and erect and bent shoots of bent canopy. Vertical bars with the same letters are not significantly different at $P \leq 0.05$. Error bars represent standard errors estimated using SAS MIXED procedure.

Because shoots are usually bent toward the ground, it is likely that the xylem tissues of inner kink (compression side) are more damaged than the outer portion (lateral and tension sides) resulting in impaired water transport on the compression side of the shoot. This is supported by our results that the leaves attached to the lower side of bent shoots exhibited reduced rates of $A$ and $g_{s}$ (Table 3). Frederickesen et al. (1994) observed that bending damage was greatest on the compression side of bent stems in loblolly pine while the damage to stem tissue did not affect hydraulic conductivity.

Flower bud removal did not appear to influence the gas-exchange parameters of erect shoots. Minor reductions $(\approx 10 \%)$ in $A$ and $E$ due to flower removal, however, were observed in bent shoots (Table 2). A developing flower bud is an active sink of carbohydrates and its removal may cause an imbalance in the source/sink relations of a shoot. Sink removal or destruction was thought to alter photosynthetic capacity (Pinkard and Beadle, 1998). Our experimental results suggest that practicing flower removal simultaneously with shoot-bending might exacerbate the bending effect on carbon assimilation rate. This could indicate that bending damages both phloem and xylem (in the short term), and that removing the sink reduces photosynthesis because mobilization of the carbon assimilates is restricted until the phloem heals. In commercial practice it is believed that the removal of the flower bud with bending would redirect the assimilates from the bent shoots to newly developing flowering shoots rather than investing them on unusable flower buds. If bending inhibits phloem transport, then in the short term it may have little benefit to the carbon economy of the erect flowering shoots. Further experiments such as girdling experiments may be useful to elucidate the relations between the phloem damage due to bending and sink removal.

In summary, shoot-bending resulted in a reduction in net photosynthetic rates of up to $25 \%$ (Table 2). This reduction lasted about three weeks. The reduction in leaf photosynthesis may not be directly applicable to whole-canopy productivity because light distribution on and inside the bent canopy is not likely to be saturated throughout the day. Kim and Lieth (2002), based on 
simulation results, discussed that the contribution of bent shoots to whole-canopy would depend on the light availability to the bent shoots and the density of bent and erect shoots of a canopy. Under low light conditions, maintaining many bent shoots in the canopy could be detrimental to whole-canopy assimilation (Kim and Lieth, 2002; Pien et al., 2001). At a single-leaf scale, the negative effect of bending on $A$ was most pronounced at light saturated conditions (Fig. 3). $A_{\max }$ was the only parameter in the photosynthetic light response model affected by bending, indicating that the effect of bending on $A$ may be little under low light conditions. In practice, light availability on bent shoots in a rose canopy is limited, and the reduction in leaf gas-exchange rates due to bending may not lower whole crop assimilation rates significantly. Care should be taken by growers not to sever shoots when bending. More importantly, growers should balance the number of bent shoots with the light condition inside the greenhouse.

We conclude that decreased gas-exchange parameters are attributable to the water stress, demonstrated by lower stem water potential, as a result of impaired water transport due to damaged xylem vessels by shoot-bending.

\section{Literature Cited}

Cline, M.G. 1991. Apical dominance. Bot. Rev. 57:318-358.

Faber, W.R. and J.W. White. 1977. The effect of pruning and growth regulator treatment on rose plant renewal. J. Amer. Soc. Hort. Sci. 102:223-225.

Field, C.B. 1983. Allocating leaf nitrogen for the maximization of carbon gain: Leaf age as a control on the allocation program. Oecologia 56:341-347.

Fredericksen, T.S., R.L. Hedden, and S.A. Williams. 1994. Effect of stem bending on hydraulic conductivity and wood strength of loblolly pine. Can. J. For. Res. 24:442-446.

Fulton, A., R. Buchner, B. Olson, L. Schwankl, C. Gilles, N. Bertagna, J. Walton, and K. Shackel. 2001. Rapid equilibration of leaf and stem water potential under field conditions in almonds, walnuts, and prunes. HortTechnology 11:609-615.

Gonzalez-Real, M.M. and A. Baille. 2000. Changes in leaf photosynthetic parameters with leaf position and nitrogen content within a rose plant canopy (Rosa hybrida). Plant Cell Environ. 23:351-363.
Harper, J.L. 1989. The value of a leaf. Oecologia 80:53-58.

Heichel, G.H. and N.C. Turner. 1983. $\mathrm{CO}_{2}$ assimilation of primary and regrowth foliage of red maple (Acer rubrum L.) and red oak (Quercus rubra L.): Response to defoliation. Oecologia 57:14-19.

Hortensteiner, S. and U. Feller. 2002. Nitrogen metabolism and remobilization during senescence. J. Expt. Bot. 53:927-937.

Hosokawa, Z., L. Shi, T.K. Prasad, and M.G. Cline. 1990. Apical dominance control in Ipomoea nil: The influence of the shoot apex, leaves and stem. Ann. Bot. 65:547-556.

Kim, S.-H. and J.H. Lieth. 2002. Modeling photosynthesis of heterogeneous rose crop canopies in the greenhouse. Acta Hort. 593:121128.

Kim, S.-H. and J.H. Lieth. 2004. Effect of shoot-bending on productivity and economic value estimation of cut-flower roses grown in Coir and UC Mix. Scientia Hort. 99:331-343.

Kool, M.T.N. and E.F.A. Lenssen. 1997. Basal-shoot formation in young rose plants: Effects of bending practices and plant density. J. Hort. Sci. 72:635-644.

Larson, K.C. 1998. The impact of two gall-forming arthropods on the photosynthetic rates of their hosts. Oecologia 115:161-166.

Littell, R.C., G.A. Milliken, W.W. Stroup, and R.D. Wolfinger. 1996. SAS system for mixed models. SAS Inst., Cary, N.C.

Mitchell, C.A. 1996. Recent advances in plant response to mechanical stress: theory and application. HortScience 31:31-35.

Oki, L.R., J.H. Lieth, and S.A. Tjosvold. 2001. Irrigation of Rosa hybrida L. 'Kardinal' based on soil moisture tension increases productivity and flower quality. Acta Hort. 547:213-219.

Pasian, C.C. and J.H. Lieth. 1989. Analysis of the response of net photosynthesis of rose leaves of varying ages to photosynthetically active radiation and temperature. J. Amer. Soc. Hort. Sci. 114:581-586.

Pien, H., E. Bobelyn, R. Lemeur, and M.C. Van Labeke. 2001. Optimizing LAI in bent rose shoots. Acta Hort. 547:319-327.

Pinkard, E.A. and C.L. Beadle. 1998. Regulation of photosynthesis in Eucalyptus nitens (Deane and Maiden) Maiden following green pruning. Trees. 12:366-376.

Raviv, M. and T.J. Blom. 2001. The effect of water availability and quality on photosynthesis and productivity of soilless-grown cut roses. Scientia Hort. 88:257-276.

Sharkey, T.D. 1985. Photosynthesis in intact leaves of $C_{3}$ plants: Physics, physiology and rate limitations. Bot. Rev. 51:53-105.

Zieslin, N. and Y. Mor. 1981. Plant management of greenhouse roses. Formation of renewal canes. Scientia Hort. 15:67-75. 